\title{
Prenatal Diagnosis of Fetal Nasal Glioma
}

\author{
Roberto Méndez-Gallart, MD, PhD; ${ }^{1}$ Maria García-Palacios, MD, PhD; ${ }^{1}$ \\ Raquel Carracedo-Reboredo, MD; ${ }^{2}$ Pablo Rodríguez-Barca, MD, PhD; ${ }^{1}$ \\ Adolfo Bautista-Casasnovas, MD, $\mathrm{PhD}^{1}$ \\ ${ }^{1}$ Department of Pediatric Surgery, University Hospital of Santiago, Santiago de Compostela, A Coruña, Spain \\ ${ }^{2}$ University Hospital of Santiago, Santiago de Compostela, A Coruña, Spain
}

\begin{abstract}
A 34-year-old primigravida with no significant medical history underwent a routine ultrasound at 21 weeks' gestation. Fetal sonography revealed the presence of a solid mass, $14 \mathrm{~mm} \times 19 \mathrm{~mm}$ in size, arising from the region of the glabella (Figure 1B). No other abnormalities were detected. Fetal MRI was performed at 21 weeks (Figure 2A) to clearly define the lesion and rule out calvarial defects. The patient chose to continue with the pregnancy. A male fetus was uneventfully delivered at 39 weeks. The presence of a solid friable mass located in the left internal canthus was noticed (Figure 2B). The mass was resected with no complications at 2 weeks of age (Figure 2C), and pathological study confirmed the presence of neuroglial heterotopic tissue (nasal glioma). Although benign in nature, gliomas are cosmetically unfavorable, and early surgical intervention is the treatment of choice to minimize nasal distortion. ${ }^{1,2}$ Differential diagnosis includes encephalocele, teratoma, dermoid cyst, dacryocystocele, retinoblastoma, and hemangioma. ${ }^{2,3}$ Prenatal suspected diagnosis and assessment is of paramount relevance.
\end{abstract}

Consent to publish these images was obtained from the parents.

\section{J Obstet Gynaecol Can 2017; (घ):1-2}

https://doi.org/10.1016/j.jogc.2017.02.002

Copyright @ 2017 The Society of Obstetricians and Gynaecologists of Canada/La Société des obstétriciens et gynécologues du Canada.

Published by Elsevier Inc. All rights reserved.

\section{REFERENCES}

1. Tonni G, Lituania M, Bonasoni MP, et al. Prenatal ultrasound and histological diagnosis of fetal nasal glioma (heterotopic central nervous system tissue): report of a new case and review of the literature. Arch Gynecol Obstet 2011;283(Suppl 1):55-9.

2. De Biasio P, Scarso E, Prefumo F, et al. Prenatal diagnosis of a nasal glioma in the mid trimester. Ultrasound Obstet Gynecol 2006;27:571-3.

3. Okumura M, Francisco RP, Lucato LT, et al. Prenatal detection and postnatal management of an intranasal glioma. J Pediatr Surg $2012 ; 47: 1951-4$

Figure 1.

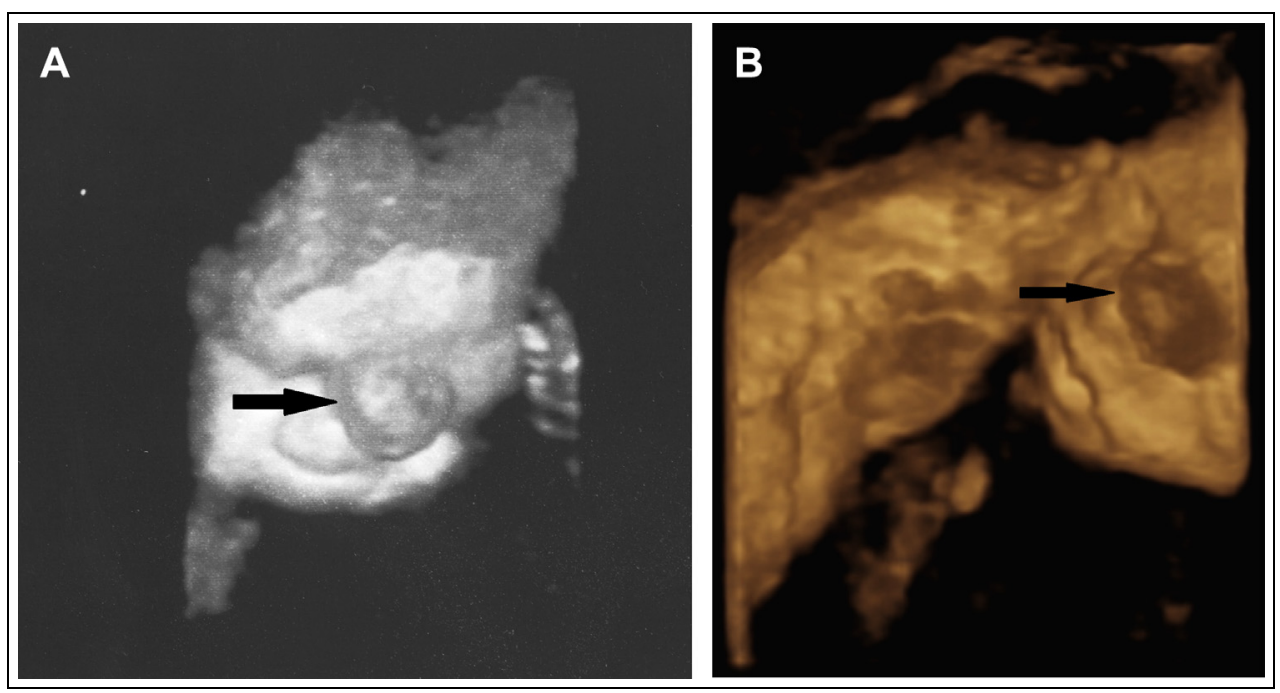


Figure 2.

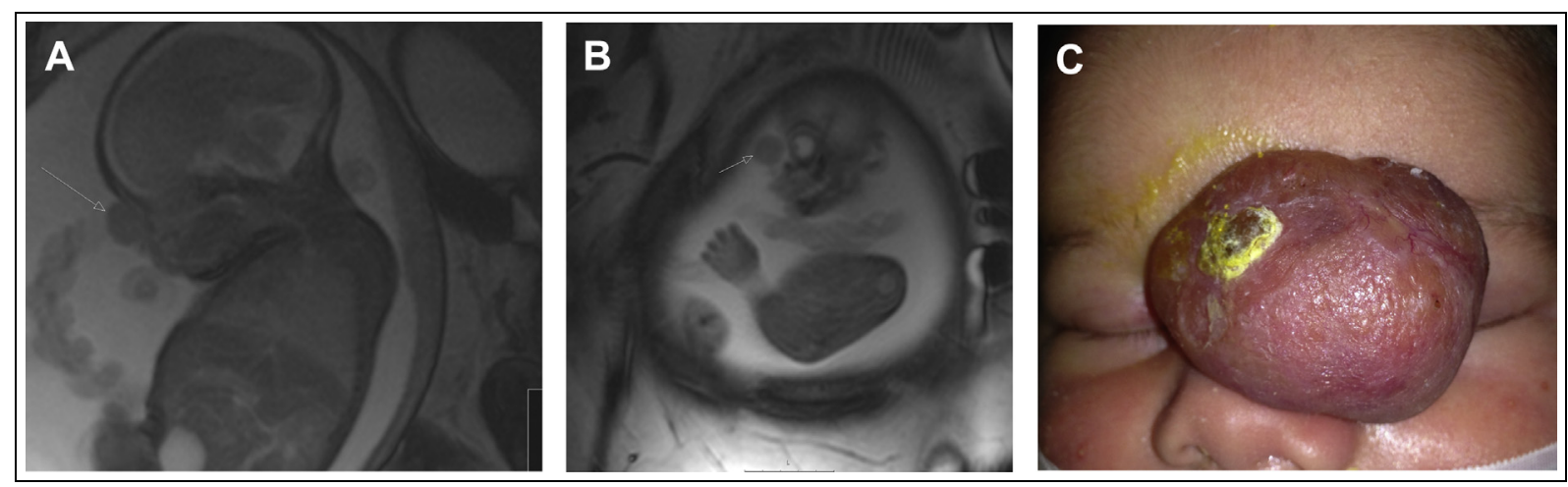

